\title{
Identification of sesquisabinene B in carrot (Daucus carota L.) leaves as a compound electrophysiologically active to the carrot psyllid (Trioza apicalis Förster)
}

\author{
Rizan Rahmani ${ }^{1} \cdot$ Fredrik Andersson $^{1} \cdot$ Martin N. Andersson $^{2} \cdot$ Jothi Kumar Yuvaraj $^{2} \cdot$ Olle Anderbrant $^{2}$. \\ Erik Hedenström ${ }^{1}$
}

Received: 20 December 2018 / Accepted: 8 March 2019 / Published online: 14 March 2019

(c) The Author(s) 2019

\begin{abstract}
The Carrot psyllid, Trioza apicalis Förster (Homoptera: Psylloidea: Triozidae) is one of the major insect pests of carrots (Daucus carota L.) in parts of northern and central Europe. Gas chromatography-single-sensillum recording (GC-SSR) previously confirmed several active compounds in a carrot leaf extract, but the most active compound remained unidentified. Mass fragmentation patterns observed from the unidentified active compound when analyzed by gas chromatography and mass spectrometry (GC-MS) was used to propose $\beta$-sesquiphellandrene and $\alpha$-cis-bergamotene to be candidates as the unidentified compound. The compounds were synthesized and their mass spectra were nearly identical with the unknown active compound. But, the retention times differed from the compound in the carrot leaf extract. Thus, to obtain the unidentified compound pure enough and in adequate amounts for nuclear magnetic resonance (NMR) analysis, preparative gas chromatography was applied to separate and concentrate this biologically active compound. Analysis by liquid chromatography quadrupole time of flight mass spectrometry (LC-QTOF) confirmed the unidentified compound to be a compound with the formula of $\mathrm{C}_{15} \mathrm{H}_{24}$ and together with GC-MS, ${ }^{1} \mathrm{H}$ and ${ }^{13} \mathrm{C}$ NMR analysis sesquisabinene $\mathrm{B}$ was identified as the unidentified compound in the extract. GC-SSR was then used to finally confirm the biological activity of sesquisabinene B isolated from the carrot leaf extract via preparative GC.
\end{abstract}

Keywords Synthesis $\cdot \beta$-Sesquiphellandrene $\cdot \alpha$-cis-Bergamotene $\cdot$ Preparative gas chromatography $\cdot$ Single-sensillum recording $\cdot$ Analysis

\section{Introduction}

The carrot psyllid (Trioza apicalis Förster) is one of the major insect pests of carrot (Daucus carota $\mathrm{L}$.) in many parts of northern and central Europe (Láska 1974; Rygg 1977;

Communicated by Marko Rohlfs.

Electronic supplementary material The online version of this article (https://doi.org/10.1007/s00049-019-00280-6) contains supplementary material, which is available to authorized users.

Erik Hedenström

erik.hedenstrom@miun.se

1 Eco-Chemistry, Department of Chemical Engineering, Mid Sweden University, 85170 Sundsvall, Sweden

2 Department of Biology, Lund University, 22362 Lund, Sweden
Munyaneza et al. 2010). The females lay their eggs on the carrot leaves early in the summer, and soon after the leaves become discolored and curl up due to phloem feeding of adults and nymphs. Furthermore, the root growth is distorted and reduced, resulting in non-marketable products. In addition, the psyllid and affected carrots are associated with the plant pathogen "Candidatus Liberibacter solanacearum" (Munyaneza et al. 2010, 2012). The new generation of psyllids migrates at the end of the season to nearby conifers, especially Norway spruce, Picea abies (L.) Karst., where they spend the winter (Kristoffersen and Anderbrant 2005, 2007). As with most insects, one can assume that several processes in the life cycle of carrot psyllids are guided, at least in part, by volatile chemical signals, e.g., finding carrots in the spring, finding a mate and localizing the overwintering habitat. A previous investigation found a number of compounds from carrots and conifers that elicited physiological responses in the psyllid antenna (Kristoffersen et al. 
2008), e.g., (Z)-3-hexenal, terpinolene and terpinene-4-ol of conifer origin and also $\alpha$-phellandrene and $(Z)-\alpha$-bisabolene of carrot origin. However, the most active compound from carrot leaves remained unidentified and it was only noted that its mass spectrum was similar to that of bergamotene. Thus, it was needed to perform purification and a structural investigation to identify the correct molecular structure.

\section{Materials and methods}

\section{Plant material}

D. carota (various cultivars) was grown in a greenhouse at the Mid Sweden University. The first planting was done on October 26, 2015, and the second was done on February 3, 2016. Seeds were sown by hand in pots filled with peat soil and with a spacing of $5 \mathrm{~cm}$. Pots were enclosed in a plastic container to keep the humidity in the soil and watered manually when required.

\section{Chemicals}

All extraction and liquid chromatography solvents used were of analytical grade and they were used as received from their commercial suppliers without further purification, purchased from VWR International AB, Stockholm, Sweden.

\section{Extraction}

All extractions were done by pure $n$-pentane (LC grade), in two steps. Every 2 weeks carrot leaves were freshly collected, weighted (20-60 g) and separately inserted to a $1000 \mathrm{ml}$ flask with $400 \mathrm{ml}$ pentane, covered by aluminum foil and kept at room temperature for $24 \mathrm{~h}$. The second extraction was done in the same way but for $2 \mathrm{~h}$. All extracts, from $1311 \mathrm{~g}$ of leaves in total, were collected, pooled and the solvent evaporated to give $1.7293 \mathrm{~g}$. To estimate the amount of sesquisabinene $\mathrm{B}$ in the extract we used $n$-pentadecane as an external standard and GC-FID for analysis. The amount was determined in extracts from leaves grown for 5, 7, and 11 weeks and the mean values were estimted to be 3,1 and $1 \mu \mathrm{g}$ of sesquisabinene B/g carrot leaves, respectively.

\section{Purifications}

The purification was performed in three steps. First, the carrot volatile extracts were filtered using a sterilized pipette, filled with glass wool and magnesium sulphate, to remove water and impurities from the extract. Then, the extracts were purified by flash chromatography with Fluka Silica gel 60 (230-400 mesh particle size) using stepwise gradient elution with $0 \%, 2-8 \%$ of ethyl acetate in $n$-pentane in steps of
$2 \%$, and finally $100 \%$, on a P2 column, $81 \mathrm{~g}$ of silica gel, with elution volumes of $120 \mathrm{ml}$ for fraction 2-8 and with double elution volume $(240 \mathrm{ml})$ for $0 \%$.

Thin layer chromatography (TLC) was performed on silica gel plates (Fluka, pre-coated aluminum foil) eluted with $40 \%$ of ethyl acetate in cyclohexane and then sprayed with vanillin in sulfuric acid followed by heating with a heat gun to visualize organic compounds in the fractions. Fractions $13-25$ (2-8\% of ethyl acetate in $n$-pentane), containing the active compound, were collected, pooled and analyzed by GC-FID for confirmation as described below.

A 3300 Agilent (Santa Clara, CA, USA) GC-FID equipped with a preparative column, DB-5 column $(30 \mathrm{~m} \times 0.53 \mathrm{~mm}$ i.d., $5.00 \mu \mathrm{m}$ film thickness; Agilent $)$ and connected to a preparative fraction collector (PFC) was used for the purification and concentration steps. The oven temperature program used started at $150{ }^{\circ} \mathrm{C}$ and held for $2 \mathrm{~min}$, then increased up to $250{ }^{\circ} \mathrm{C}$ at $7{ }^{\circ} \mathrm{C} / \mathrm{min}$, with a total run time of $16.3 \mathrm{~min}$.

The GC was run with a constant flow of $4 \mathrm{ml} / \mathrm{min}$ of $\mathrm{He}$ with PFC switch temperature of $240{ }^{\circ} \mathrm{C}$, transfer line temperature of $230{ }^{\circ} \mathrm{C}$ and four $100 \mu \mathrm{l}$ glass fraction collectors. In each run $2 \mu \mathrm{l}$ of the sample was injected in splitless mode using auto-injector. One percent of the effluent passed to the flame ionization detector (FID) for detection and the remaining $99 \%$ were directed to the fraction collector. After about 320 injections the sample in each trap was washed out with $n$-pentane and analysed by GC to check the chemical purity.

\section{Analysis}

GC analyses were carried out using a 3300 Agilent GC-FID, equipped with an HP-5ms column $(30 \mathrm{~m} \times 0.25 \mathrm{~mm}$ i.d., $0.25 \mu \mathrm{m}$ film thickness; Agilent), using $\mathrm{N}_{2}$ as carrier gas. The active compound was confirmed with GC-MS, using a Hewlett-Packard 6890N GC with an HP 5973 mass spectrometer (MS); equipped with an HP-5 ms column as above, operating in electron impact ionization mode (EI, $70 \mathrm{eV}$ ). The mobile phase (flow rate $=1.0 \mathrm{ml} / \mathrm{min}$ ) was helium, the split/splitless injector was operated in splitless mode for $2.51 \mathrm{~min}$. Separations were performed for both instruments using a temperature program in which the column initially was held at $70{ }^{\circ} \mathrm{C}$ for $2 \mathrm{~min}$, then increased to $250{ }^{\circ} \mathrm{C}$ at $10{ }^{\circ} \mathrm{C} / \mathrm{min}$.

Nuclear magnetic resonance (NMR) spectra were recorded on a Bruker Avance $500\left(500 \mathrm{MHZ}{ }^{1} \mathrm{H}, 125.8 \mathrm{MHZ}\right.$ ${ }^{13} \mathrm{C}$ ) spectrometer using $\mathrm{CDCl}_{3}$ and $\mathrm{C}_{6} \mathrm{D}_{6}$ as solvents, all shifts are reported in ppm. One-dimensional ${ }^{1} \mathrm{HNMR}$ spectra of purified unknown compound with 17,280 scans, ${ }^{13} \mathrm{CMNR}$ with 37,728 scans in $\mathrm{CDCl}_{3}$ at $298^{\circ} \mathrm{Kelvin}\left(24.85^{\circ} \mathrm{C}\right)$ and Dept 90 and Dept 135 two-dimensional NMR, Homodecoupled Noesy and Cosy in $\mathrm{C}_{6} \mathrm{D}_{6}$ as solvent at $280^{\circ}$ Kelvin $\left(6.85^{\circ} \mathrm{C}\right)$ were acquired. 
HPLC-MS analyses were performed on a G1316C HPLC instrument (Agilent) in normal phase, equipped with a binary pump, DAD, an Agilent 6520 Accurate mass quadrupole-time of flight mass spectrometry (Q-TOF), and HiP sampler in APCI with positive mode. Chromatographic separations were carried out on an Agilent Eclipse plus C18 column $(2.1 \times 100 \mathrm{~mm}, 1.8 \mu \mathrm{m})$ at $25^{\circ} \mathrm{C}$. Elution was performed at a flow rate of $0.3 \mathrm{~mL} / \mathrm{min}$. Water (A) and methanol (B) were used as a mobile phase. Gradient elution was used as follows: $100 \% \mathrm{~B}$ (13 $\mathrm{min}), 100 \% \mathrm{~A}(3 \mathrm{~min})$. The injection volume was $1.0 \mu \mathrm{L}$ and the detection wavelengths were 210,230 , and $254 \mathrm{~nm}$.

\section{Confirmation of physiological activity: single-sensillum recordings (SSR)}

Insects for testing the activity of carrot leaf extract were collected in early June 2011 from a carrot field in Hedrum, Larvik, southern Norway, and those for the remaining recordings came from a laboratory culture held at Natural Resources Institute Finland (Luke, formerly MTT Agrifood Research Finland) in Jokioinen, as described by Nissinen et al. (2007). Adult male and female T. apicalis were mounted for electrophysiological analysis as previously described (Kristoffersen et al. 2008). Standard SSR and GC-SSR using tungsten microelectrodes and established experimental procedures were conducted on a Syntechbased platform (Kirchzarten, Germany) following the settings described in Andersson et al. (2012) and Yuvaraj et al. (2013). Recordings were made from both sexes and from all four sensillar cavities, housing sensilla S1-S4 (from proximal to distal segments) (Kristoffersen et al. 2006, 2008). Initially, the physiological activity of compounds in a carrot (D. carota) leaf extract ( $1 \mathrm{~g}$ of leaf material extracted in $1 \mathrm{ml}$ re-distilled hexane for $3 \mathrm{~h}$ at room temperature) was analyzed by means of GC-SSR, using an HP 5890 Series II plus GC with an HP1 column ( $30 \mathrm{~m}, 0.25 \mathrm{~mm}$ i.d., $0.25 \mu \mathrm{m}$ film thickness; Agilent) and the experimental conditions described in Kristoffersen et al. (2008). The GC oven was programmed as follows: $50{ }^{\circ} \mathrm{C}$ for $2 \mathrm{~min}$, and then raised by $10{ }^{\circ} \mathrm{C} / \mathrm{min}$ to $230{ }^{\circ} \mathrm{C}$ (held for $5 \mathrm{~min}$ ). The same GC-SSR set-up was used to confirm the physiological activity of the purified compound, but this time the GC was equipped with an HP-INNOWax PEG column ( $30 \mathrm{~m}, 0.25 \mathrm{~mm}$ i.d., $0.25 \mu \mathrm{m}$ film thickness; Agilent), and the following temperature program was used: $50{ }^{\circ} \mathrm{C}$ initial (held for $2 \mathrm{~min}$ ) and then increased at a rate of $8{ }^{\circ} \mathrm{C} / \mathrm{min}$ up to $200{ }^{\circ} \mathrm{C}$ (held for $5 \mathrm{~min}$ ). The inlet temperature was $230{ }^{\circ} \mathrm{C}$ and the detector temperature was $250{ }^{\circ} \mathrm{C}$. Finally, dose-response tests of the purified compound were performed using standard SSR, with the compound diluted in paraffin oil, and applied in $10 \mu \mathrm{l}$ aliquots on filter paper strips inside standard Pasteur pipette stimulus cartridges (for additional experimental details, see
Yuvaraj et al. (2013). All neuronal responses were analyzed using AutoSpike v3.3 (Syntech). Dose-dependent responses were quantified by counting the number of action potentials (spikes) during the first $0.5 \mathrm{~s}$ of the response, and then subtracting the number of spikes during the 0.5-s pre-stimulation period. This number was then doubled to obtain a response in spikes/s $(\mathrm{Hz})$.

\section{Results and discussion}

The aim of this study was to chemically identify a volatile substance from carrot leaf extract that is biologically active to the psyllid. Initially, gas chromatography-single-sensillum recording (GC-SSR) was used to confirm several active compounds in the carrot leaf extract, but the most active compound remained unidentified as described in Kristoffersen et al. (2008). Then the leaf extract was analysed by GC-MS and the mass fragmentation pattern observed for the unidentified compound was compared with NIST MS 2.0 mass spectral libraries and the best hit was found for $\beta$-sesquiphellandrene. After synthesizing the compound (see supplementary material for full details on the synthesis) the mass spectrum was nearly identical with the unknown active compound but the retention time differed from the active compound in the extract. Thus, we looked for the second best hit from the NIST MS 2.0 mass spectral libraries that was another sesquitepenes, i.e., $\alpha$-cis-bergamotene and also this compound was synthesized (see supplementary material for full details on the synthesis). This synthetic compound was confirmed to have a similar mass spectrum and the same retention time as the unknown in the carrot extract. But, later we showed that the synthetic $\alpha$-cis-bergamotene differed in GC retention time from the active unknown compound when tested on GC column with another stationary phase (unpublished result). $\alpha$-cis-Bergamotene was also proved not to be antennally active (unpublished results).

Due to the uncertainty of just using the ranking proposals it was decided to perform a more thorough purification and structural investigation of this GC-SSR active compound. The best method for identification of the molecular structure should be NMR, but a drawback is the demand of a chemically pure sample in amounts that might be difficult to obtain from the interesting non-polar part of the extract. A possible method to purify and concentrate the unknown might be by applying preparative GC (Zuo et al. 2013; McNair and Miller 2009). Thus, after liquid extraction of carrot leaves, samples were concentrated and then pre-purified by flash chromatography to eliminate and remove more of the polar part of the matrix. A GC with a wide bore DB-5 column coupled to a PFC was applied as the third purification and concentration step. 
The pre-purified mixture contained just a small amount of the unknown compound of interest eluting at 11.523 min (Fig. 1a), but after the preparative GC separation and concentration the compound was obtained in $85 \%$ purity (Fig. 1b). The GC-MS of the unknown compound showed a possible molecular ion (M+) of $204 \mathrm{~m} / \mathrm{z}$ (Fig. 1c). The purified compound's exact mass was analyzed by LCQTOF and shown to be 205.1951 for $(\mathrm{M}+\mathrm{H})^{+}$in positive mode. The relative isotopic mass was used by the Agilent's
Masshunter Qualitative software to calculate the molecule formula $\mathrm{C}_{15} \mathrm{H}_{24}$ which might correlate to a sesquiterpene.

From the molecule formula of $\mathrm{C}_{15} \mathrm{H}_{24}$ the double bond equivalents (DBE) were calculated to four and led to the assumption that the unknown component might be a sesquiterpene with one ring and three double bonds, or two rings and two double bonds. To clarify this further analyses with ${ }^{1} \mathrm{H}$ and ${ }^{13} \mathrm{C}$ NMR were conducted. The presence of two double bonds was obvious by ${ }^{13} \mathrm{CNMR}$ and three
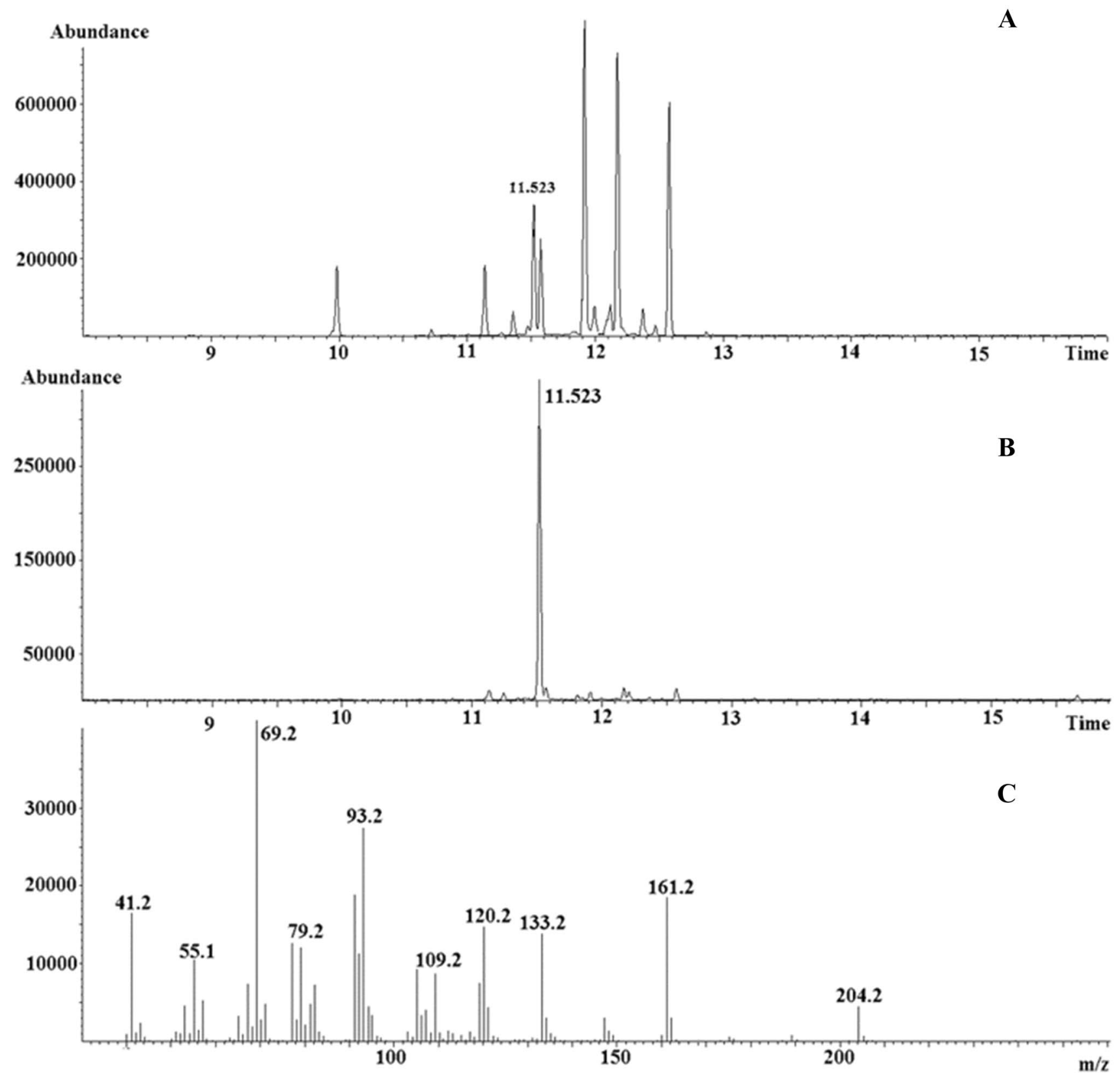

Fig. 1 GC-MS chromatogram of; a $D$. carota leaf extract after LC purification; b unknown extract compound collected after preparative gas chromatographic separation with $85 \%$ chemical purity and; $\mathbf{c}$ mass spectrum of unknown extract compound collected after prepara- tive gas chromatographic separation with $85 \%$ chemical purity. The analysis was performed on a HP-5ms column, the column temperature started from $70{ }^{\circ} \mathrm{C}$, held for $2 \mathrm{~min}$ and then increased by $10{ }^{\circ} \mathrm{C} /$ $\min$ up to $250{ }^{\circ} \mathrm{C}$ 
$-\mathrm{CH}$ groups, six $-\mathrm{CH}_{2}$ and three $-\mathrm{CH}_{3}$ groups, respectively, were confirmed from Dept 90 and 135. Therefore, the unknown compound might contain two rings and two double bounds. We used the formula browser in NIST Chemistry WebBook, SRD 69 to obtain a list of around 600 compounds with molecule formula $\mathrm{C}_{15} \mathrm{H}_{24}$. We then obtained from the ChemDraw software ${ }^{1} \mathrm{H}$ and ${ }^{13} \mathrm{C}$ NMR spectra predictions for over 200 of the 600 listed compounds. Finally, were all the predicted NMR spectra compared with the spectra of the unknown compound and thereby we ended up with two compounds with similar spectra to the unknown, i.e., sesquisabinene A and B (Fig. 2). Sesquisabinene A has been found in, e.g., pepper (Piper nigrum) (Fuerstner and Schlecker 2008) and Xanthium spinosum (Andreani et al. 2017), and sesquisabinene B in essential oil from e.g. Helianthus tuberosus (Radulovic and Dordevic 2014) and Santalum spicatum (Moniodis et al. 2015).
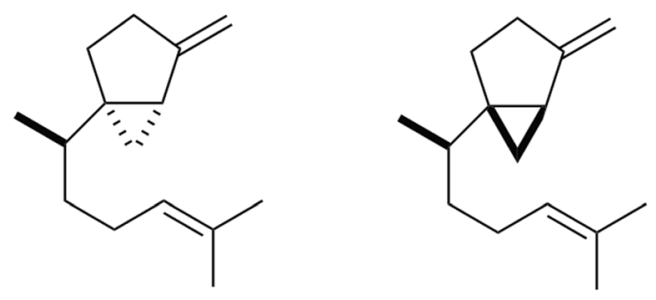

Sesquisabinene A
To determine if the unidentified compound was sesquisabinene $\mathrm{A}$ or sesquisabinene $\mathrm{B}$, a more thorough examination of the ${ }^{1} \mathrm{HNMR}$ data was performed by comparison of literature data for sesquisabinene A and B (Fuerstner and Schlecker 2008) with the unknown compound. (Table 1) For the unknown compound the protons were assigned at S 5.08-5.17, 4.80, 4.62, 2.15, 2.03-1.97, 1.82-1.73, 1.68, $1.60,1.44-1.37,1.24-1.17,0.94$ and the chemical shifts showed similarity to the shifts for the protons of both sesquisabinene A and B (Table 1). But, in the downfield proton signals at $\delta 0.66(\mathrm{ddd}, 1 \mathrm{H}), \delta 0.74(\mathrm{dd}, 1 \mathrm{H})(\mathrm{m}, 1 \mathrm{H})$ and $\delta 1.56-1.51(\mathrm{~m}, 1 \mathrm{H})$ we observed some differences. These signals originated from a methylene group and a methane group in the cyclopropane ring which is in trans position to the methyl group in sesquisabinene $\mathrm{A}$ and $c i s$ position to the methyl group in sesquisabinene B. Based on the differences and similarities between sesquisabinene $A$ and $B$ and the unknown compound in this part of the spectra it was<smiles>C=C1C=CC([C@@H](C)CCC=C(C)C)CC1</smiles>

$\beta$-Sesquiphellandrene

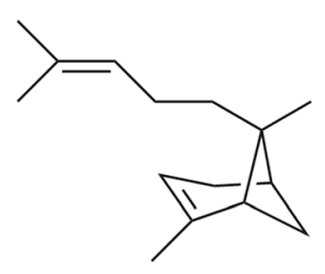

$\alpha$-cis-Bergamotene

Fig. 2 Possible identities of the unknown compound in the carrot leaf extract with molecule formula $\mathrm{C}_{15} \mathrm{H}_{24}$

Table 1 Comparison of the ${ }^{1} \mathrm{HNMR}$ data of the unidentified active compound in carrot leaf extract with previously reported data for sesquisabinene A and B (Fuerstner and Schlecker 2008)

\begin{tabular}{lll}
\hline Sesquisabinene A & Sesquisabinene B & Unidentified compound \\
\hline${ }^{1} \mathrm{HNMR}\left(\mathrm{CDCl}_{3}\right)$ & & $5.08-5.17(\mathrm{~m}, 1 \mathrm{H})$ \\
$5.12-5.06(\mathrm{~m}, 1 \mathrm{H})$ & $5.13-5.07(\mathrm{~m}, 1 \mathrm{H})$ & $4.80(\mathrm{~s}, 1 \mathrm{H})$ \\
$4.80(\mathrm{~s}, 1 \mathrm{H})$ & $4.80(\mathrm{~s}, 1 \mathrm{H})$ & $4.62(\mathrm{~s}, 1 \mathrm{H})$ \\
$4.62(\mathrm{~s}, 1 \mathrm{H})$ & $4.62(\mathrm{~s}, 1 \mathrm{H})$ & $2.15(\mathrm{dd}, J=16.0,9.2 \mathrm{HZ}, 1 \mathrm{H})$ \\
$2.14(\mathrm{dd}, J=16.1,7.3 \mathrm{HZ}, 1 \mathrm{H})$ & $2.15(\mathrm{dd}, J=15.8,9.2 \mathrm{HZ}, 1 \mathrm{H})$ & $2.03-1.97(\mathrm{~m}, 3 \mathrm{H})$ \\
$2.06-1.92(\mathrm{~m}, 3 \mathrm{H})$ & $2.08-1.94(\mathrm{~m}, 3 \mathrm{H})$ & $1.82-1.73(\mathrm{~m}, 1 \mathrm{H})$ \\
$1.77-1.66(\mathrm{~m}, 1 \mathrm{H})$ & $1.82-1.71(\mathrm{~m}, 1 \mathrm{H})$ & $1.68(\mathrm{~s}, 3 \mathrm{H})$ \\
$1.68(\mathrm{~d}, J=1.1 \mathrm{~Hz}, 3 \mathrm{H})$ & $1.68(\mathrm{~s}, 3 \mathrm{H})$ & $1.66-1.58(\mathrm{~m}, 1 \mathrm{H})$ \\
& $1.65-1.59(\mathrm{~m}, 1 \mathrm{H})$ & $1.60(\mathrm{~s}, 3 \mathrm{H})$ \\
$1.60(\mathrm{bs}, 1 \mathrm{H}+3 \mathrm{H})$ & $1.61(\mathrm{~s}, 3 \mathrm{H})$ & $1.56-1.51(\mathrm{~m}, 1 \mathrm{H})$ \\
& $1.52(\mathrm{dd}, J=8.2,3.4 \mathrm{~Hz}, 1 \mathrm{H})$ & $1.44-1.37(\mathrm{~m}, 1 \mathrm{H})$ \\
$1.51-1.42(\mathrm{~m}, 1 \mathrm{H})$ & $1.47-1.35(\mathrm{~m}, 1 \mathrm{H})$ & $1.27-1.17(\mathrm{~m}, 2 \mathrm{H})$ \\
$1.35-1.18(\mathrm{~m}, 2 \mathrm{H})$ & $1.30-1.16(\mathrm{~m}, 2 \mathrm{H})$ & $0.94(\mathrm{~d}, J=6.6 \mathrm{~Hz}, 3 \mathrm{H})$ \\
$0.93(\mathrm{~d}, J=6.7 \mathrm{~Hz}, 3 \mathrm{H})$ & $0.94(\mathrm{~d}, J=6.5 \mathrm{~Hz}, 3 \mathrm{H})$ & $0.74(\mathrm{dd}, J=4.3,3.6 \mathrm{~Hz}, 1 \mathrm{H})$ \\
$0.66(\mathrm{dd}, J=4.3,3.5 \mathrm{~Hz}, 1 \mathrm{H})$ & $0.74(\mathrm{dd}, J=4.4,3.5 \mathrm{~Hz}, 1 \mathrm{H})$ & $0.65(\mathrm{ddd}, J=8.1,4.2,1.0 \mathrm{~Hz}, 1 \mathrm{H})$ \\
$0.57(\mathrm{ddd}, J=8.2,4.6,0.6 \mathrm{~Hz}, 1 \mathrm{H})$ & $0.66(\mathrm{ddd}, J=8.2,4.6,1.2 \mathrm{~Hz}, 1 \mathrm{H})$ & \\
\hline
\end{tabular}


concluded the active compound was sesquisabinene B as the similarity is closer to sesquisabinene B.

Table 2 Comparison of the ${ }^{13} \mathrm{CNMR}$ data of the unidentified active compound in carrot leaf extract with previously reported data for sesquisabinene A and B (Fuerstner and Schlecker 2008)

\begin{tabular}{lcc}
\hline Sesquisabinene A & Sesquisabinene B & $\begin{array}{l}\text { Unidentified } \\
\text { compound }\end{array}$ \\
\hline${ }^{13}$ CNMR $\left(\mathrm{CDCl}_{3}\right)$ & & \\
154.2 & 154.5 & 154.5 \\
131.1 & 131.2 & 131.2 \\
125.0 & 124.9 & 124.9 \\
101.8 & 101.6 & 101.6 \\
37.8 & 38.0 & 38.0 \\
36.7 & 36.8 & 36.8 \\
34.6 & 35.2 & 35.2 \\
31.2 & 29.7 & 29.7 \\
28.8 & 29.0 & 29.0 \\
26.7 & 26.3 & 26.3 \\
26.1 & 26.2 & 26.2 \\
25.7 & 25.7 & 25.7 \\
18.0 & 18.3 & 18.3 \\
17.7 & 17.7 & 17.7 \\
16.1 & 17.4 & 17.4 \\
\hline
\end{tabular}

A

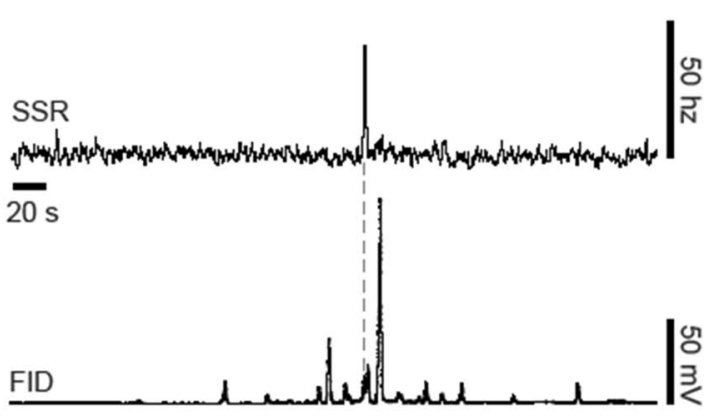

B

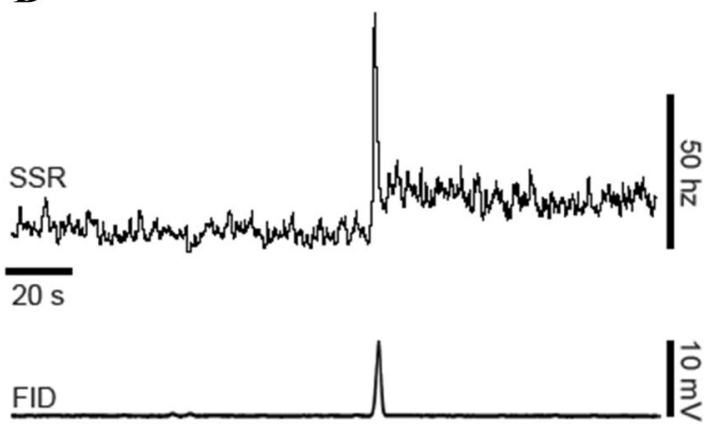

Fig. 3 GC-FID coupled single-sensillum recordings (SSR) showing neuronal responses to sesquisabinene B present in Daucus carota leaf extract (a), and purified sesquisabinene B (b), in female S1 and S3 sensilla, respectively. Upper traces show SSR responses; lower
Comparing the ${ }^{13} \mathrm{CNMR}$ data of the unidentified compound in the extract with data from the literature for sesquisabinene A and B (Fuerstner and Schlecker 2008) the carbons at $\delta 35.2,29.7$ and 17.4 for the unknown compound are significantly closer to the chemical shifts for the two methylene carbons in the five membered ring and for the methyl carbon in alkyl chain in sesquisabinene B than in sesquisabinene A (Table 2).

Thus, the diastereomers of sesquisabinene A and B, were distinguishable by differences in chemical shifts from both ${ }^{13} \mathrm{CNMR}$ and ${ }^{1} \mathrm{HNMR}$ data as shown in Tables 1 and 2, confirming the unknown compound to be sesquisabinene $\mathrm{B}$.

\section{Confirmation of physiological activity}

The four olfactory sensilla of T. apicalis all contain three olfactory sensory neurons (OSNs) that can be distinguished based on differences in spike amplitudes (labelled A, B and C cells in order of decreasing amplitude). GC-SSR using carrot leaf extract confirmed previous results (Kristoffersen et al. 2008), i.e., that the peak to be identified as sesquisabinene $\mathrm{B}$ elicited clear responses in the $\mathrm{C}$ cells of sensilla S1, S2, and S3 (Fig. 3a). Subsequent GC-SSR runs using the purified product (sesquisabinene B) further confirmed its physiological activity in sensilla $\mathrm{S} 2$ and $\mathrm{S} 3$ of both
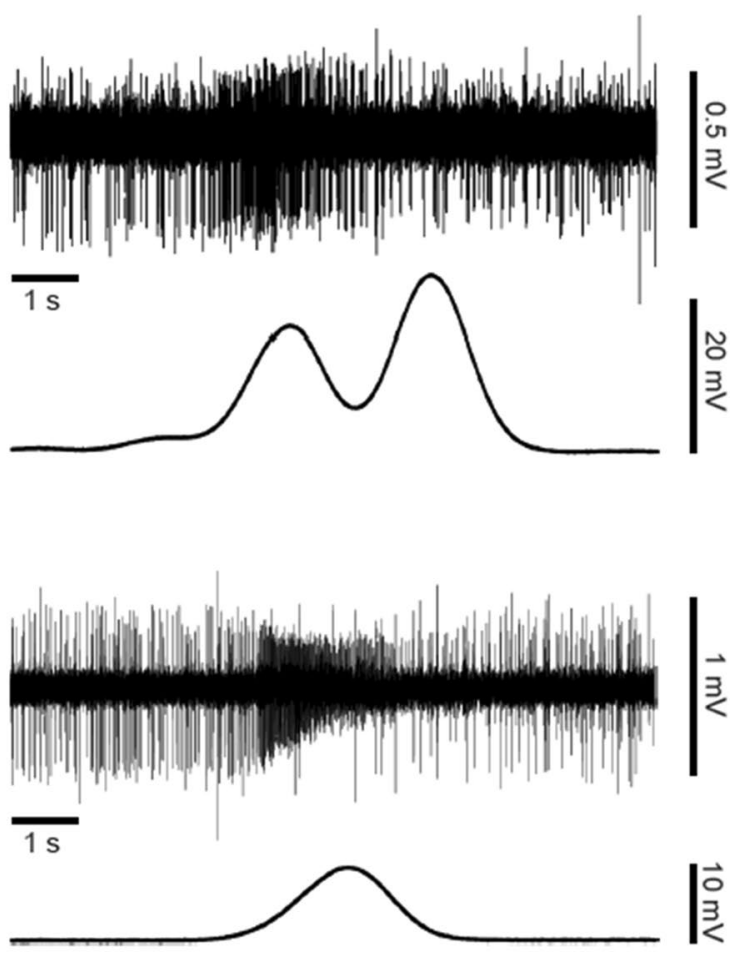

traces show the GC-FID signal. On the left are $400 \mathrm{~s}$ (a) or $200 \mathrm{~s}$ (b) excerpts; on the right are $10 \mathrm{~s}$ excerpts from the same recordings. Note that different GC-columns were used in $\mathbf{a}$ and $\mathbf{b}$ 


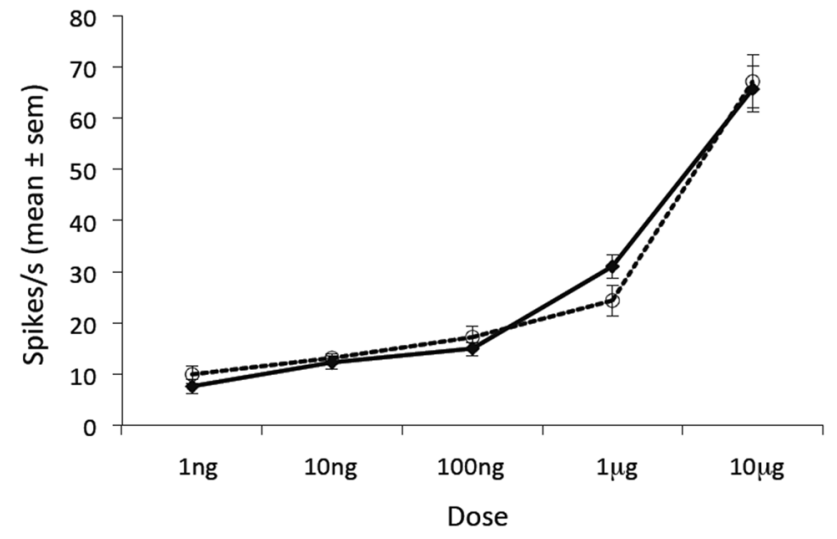

Fig. 4 Dose-response curves for the C neuron in S2 (solid line) and $\mathrm{S} 3$ (dashed line) to the purified sesquisabinene $\mathrm{B}$, showing the mean values of 4 males and 2 females for $\mathrm{S} 2\left(N_{\text {total }}=6\right)$ and of 3 males and 2 females for $\mathrm{S} 3\left(N_{\text {total }}=5\right)$. Variation between individuals was low, and no differences between the sexes were observed; hence data from the two sexes were pooled

sexes (Fig. 3b). However, the previously reported (Kristoffersen et al. 2008) activity also in S4 of males could not be confirmed.

Clear dose-dependent responses to the purified sesquisabinene B were recorded from the C-neurons in sensilla S2 and S3 (Fig. 4). However, the C-neurons inside sensilla S1 and $\mathrm{S} 4$ were only weakly activated in the dose-response experiments. In summary, the specific detection of sesquisabinene B by at least two of the twelve OSNs on the T. apicalis antenna of both sexes suggests that this compound is of high importance for the ecology of this species.

\section{Conclusion}

The Carrot psyllid, Trioza apicalis Förster (Homoptera: Psylloidea: Triozidae), is one of the major insect pests on carrots (Daucus carota L.) in parts of northern and central Europe. This study chemically identified a volatile substance from carrot leaf extract that is specifically detected by olfactory sensory neurons in the psyllid antennae. The unknown compound was extracted from carrot leaves, separated and concentrated by preparative gas chromatography and its structure elucidated by LC-QTOF, GC-MS, ${ }^{1} \mathrm{H}$ and ${ }^{13} \mathrm{C}$ NMR analysis. Sesquisabinene B was identified as the unknown compound in the carrot leaf extract and GC-SSR activity was confirmed for the isolated compound. Future studies should investigate the stereochemistry of the sesquisabinene B that was isolated from the carrot leaf extract and then characterize the suspected behavioural role of the compound in the life of the carrot psyllid.
Acknowledgements We want to thank Erika Wallin for help with some of the NMR experiments, Joel Ljunggren for HPLC analysis and Anna Nilsson for help with part of the initial synthesis of $\alpha$-cis-bergamotene. We also thank Fitsumberhan Fitwi for planting carrot, harvesting the leaves and extracting them, and Anne Nissinen (Luke, Finland) and Lars-Arne Høgetveit (NLR, Viken, Norway) for providing carrot psyllids. The authors would like to thank the European Union Europe Regional Development Fund (20201370), the Region Västernorrland (17RS484), the Region Jämtland Härjedalen (16202100-4524), the Swedish Research Council for Environment, Agricultural Sciences and Spatial Planning (Formas, 217-2014-689), and C.F. Lundströms Stiftelse (1488) for financial support.

Open Access This article is distributed under the terms of the Creative Commons Attribution 4.0 International License (http://creativeco mmons.org/licenses/by/4.0/), which permits unrestricted use, distribution, and reproduction in any medium, provided you give appropriate credit to the original author(s) and the source, provide a link to the Creative Commons license, and indicate if changes were made.

\section{References}

Andersson MN, Larsson MC, Svensson GP, Birgersson G, Rundlöf M, Lundin O, Lankinen $\AA$, Anderbrant O (2012) Characterization of olfactory sensory neurons in the white clover seed weevil, Apion fulvipes (Coleoptera: Apionidae). J Insect Physiol 58:1325-1333. https://doi.org/10.1016/j.jinsphys.2012.07.006

Andreani S, Paolini J, Costa J, Muselli A (2017) Chemical composition of essential oils of Xanthium spinosum L., an invasive species of Corsica. Chem Biodivers 14:e1600148. https://doi.org/10.1002/ cbdv. 201600148

Fuerstner A, Schlecker A (2008) A gold-catalyzed entry into the sesquisabinene and sesquithujene families of terpenoids and formal total syntheses of cedrene and cedrol. Chem Eur J 14:9181-9191. https://doi.org/10.1002/chem.200801382

Henly RS, Royer DJ (1969) Preparative gas chromatography. In: Methods in enzymology, vol 14. Academic Press, Cambridge pp 450464. https://doi.org/10.1016/S0076-6879(69)14053-7

Kristoffersen L, Anderbrant O (2005) Host plant ecology of the carrot psyllid (Trioza apicalis). IOBC WPRS Bull 28(4):129-132

Kristoffersen L, Anderbrant O (2007) Carrot psyllid (Trioza apicalis) winter habitats-insights in shelter plant preference and migratory capacity. J Appl Entomol 131:174-178. https://doi.org/10.1 111/j.1439-0418.2007.01149.x

Kristoffersen L, Hallberg E, Wallén R, Anderbrant O (2006) Sparse sensillar array on Trioza apicalis (Homoptera, Triozidae) antennae-an adaptation to high stimulus levels? Arthropod Struct Dev 35:85-92. https://doi.org/10.1016/j.asd.2006.04.001

Kristoffersen L, Larsson MC, Anderbrant O (2008) Functional characteristics of a tiny but specialized olfactory system: olfactory receptor neurons of carrot psyllids (Homoptera: Triozidae). Chem Senses 33:759-769. https://doi.org/10.1093/chemse/bjn034

Láska P (1974) Studie über den Möhrenblattfloh (Trioza apicalis Först.) (Triozidae, Homoptera). Acta Sci Nat Acad Sci Bohemoslovacae Brno 8:1-44

McNair HM, Miller JM (2009) Basic gas chromatography, 2nd edn. John Wiley \& Sons, Inc., New Jersey

Moniodis J, Jones CG, Barbour EL, Plummer JA, Ghisalberti EL, Bohlmann J (2015) The transcriptome of sesquiterpenoid biosynthesis in heartwood xylem of Western Australian sandalwood (Santalum spicatum). Phytochemistry 113:79-86. https://doi.org/10.1016/j. phytochem.2014.12.009 
Munyaneza JE, Fisher TW, Sengoda VG, Garczynski SF, Nissinen A, Lemmetty A (2010) Association of "Candidatus Liberibacter solanacearum" with the psyllid, Trioza apicalis (Hemiptera: Triozidae) in Europe. J Econ Entomol 103:1060-1070. https://doi. org/10.1603/EC10027

Munyaneza JE, Sengoda VG, Stegmark R, Arvidsson AK, Anderbrant O, Yuvaraj J-K, Rämert B, Nissinen A (2012) First report of "Candidatus Liberibacter solanacearum" associated with psyllid-affected carrots in Sweden. Plant Dis 96:453. https://doi. org/10.1094/PDIS-10-11-0871

Nissinen A, Vanhala P, Holopainen JK, Tiilikkala K (2007) Short feeding period of carrot psyllid (Trioza apicalis) females at early growth stages of carrot reduces yield and causes leaf discolouration. Entomol Exp Appl 125:277-283. https://doi.org/10.111 1/j.1570-7458.2007.00628.x
Radulovic NS, Dordevic MR (2014) Chemical composition of the tuber essential oil from Helianthus tuberosus L. (Asteraceae). Chem Biodivers 11:427-437. https://doi.org/10.1002/cbdv.201300323

Rygg T (1977) Biological investigations on the carrot psyllid Trioza apicalis Förster (Homoptera, Triozidae). Meld Nor Landbrukshøgs 56:1-20

Yuvaraj JK, Andersson MN, Steinbauer M, Farnier K, Anderbrant O (2013) Specificity and sensitivity of plant odor-detecting olfactory sensory neurons in Ctenarytaina eucalypti (Sternorrhyncha: Psyllidae). J Insect Physiol 59:542-551. https://doi.org/10.1016/j. jinsphys.2013.03.004

Zuo H-L, Yang F-Q, Huang W-H, Xia Z-N (2013) Preparative gas chromatography and its applications. J Chromatogr Sci 51:704-715. https://doi.org/10.1093/chromsci/bmt040 